\title{
Ligament Balancing in Severe Osteoarthritis Knee with Large Cyst and Bursae - A Rare Case Report with Review of Literature
}

\author{
Amit Lakhani ${ }^{1}$, Ena Sharma ${ }^{2}$, Jose Antonio De Compos Martins ${ }^{3}$, Rita Alcada ${ }^{4}$ \\ ${ }^{1}$ Department of Orthopaedics, Maharishi Markandeshwar Medical College and Hospital, Kumarhatti Solan \\ Himachal Pradesh, India. ${ }^{2}$ Department of Periodontics, Maharishi Markandeshwar College of Dental \\ Sciences and Research (Deemed to Be University), Mullana Ambala, Haryana, India. ${ }^{3}$ Department of \\ Orthopaedics, Cascais Hospital, Portugal. ${ }^{4}$ Department of Physiotherapy, Cascais Hospital, Portugal.
}

\section{INTRODUCTION}

The main indication of total knee replacement (TKR) is pain and restricted range of motion of the knee. The key to a successful total knee replacement is correct alignment in flexion and extension. Here we report a case of TKR in severe osteoarthritis (O / A) knee with a large cyst on the medial side of the knee, resulting in the problem of ligament balancing and management with help of an Arthrex Internal brace. Proper diagnosis and treatment plan help to overcome the challenging cases of varus knee.

The indication of total knee replacement is pain and restricted range of motion of the knee. Several authors have reported successful outcomes on patient satisfaction in the follow-up of almost ten to fifteen years. ${ }^{1}$ Additionally, the results of surgery are satisfactiry with good implant survival. ${ }^{2}$ But some patients indeed have poor results and some may require revision surgery in a short duration. The key to a successful total knee replacement is correct alignment and stability in flexion and extension. ${ }^{3}$

The ligament after balancing of the correctly aligned knee must consider the function of the resected ligaments in flexion and extension, because in TKR both anterior cruciate ligament (ACL) and posterior cruciate ligament (PCL) are usually sacrificed. In other words, total knee replacement is a soft tissue surgery in which bone is replaced. In the varus knee, medial side structures are tight and compensatory laxity on the lateral side. So knee stability should be managed by the remaining ligamentous structures that are both medial and lateral collateral and capsular ligaments. ${ }^{4}$ The gap technique is the gold standard for ligament balancing in total knee replacement. ${ }^{5}$ That is the execution of equal medial and lateral gaps as well as balanced flexion and extension gaps. This is usually obtained by medial side release in varus knee as the medial side is contracted and lateral side release in valgus knee accordingly.

Here we report a case of TKR in severe osteoarthritis knee with a large cyst on the medial side of the knee, resulting in the problem of ligament balancing and management.
Corresponding Author:

Dr. Ena Sharma,

Department of Orthopaedics,

Maharishi Markandeshwar

Medical College and Hospital,

Kumarhatti Solan,

Himachal Pradesh, India.

E-mail:dr.sharma_ena@yahoo.co.in

DOI: $10.14260 /$ jemds/2021/249

How to Cite This Article:

Lakhani A, Sharma E, Martins JD, et al. Ligament balancing in severe osteoarthritis knee with large cyst and bursae - a rare case report with review of literature. J Evolution Med Dent Sci 2021;10(16):1174-1176, DOI: 10.14260/jemds/2021/249

Submission 08-12-2020,

Peer Review 18-02-2021,

Acceptance 25-02-2021,

Published 19-04-2021.

Copyright (c) 2021 Amit Lakhani et al. This is an open access article distributed under Creative Commons Attribution License [Attribution 4.0 International (CC BY 4.0)] 


\section{PRESENTATION OF CASE}

A 61-year-old male with severe 0 / A right knee was admitted to Cascais hospital, Lisbon for right side TKR. On examination, the patient had varus deformity with swelling on the medial side of the knee (Figure 1, 2). The range of motion (ROM) was 10 to 100 . For swelling patient underwent ultrasonography (USG) of the medial side of the knee that showed cyst under medial collateral ligament (MCL). Magnetic resonance imaging (MRI) confirmed cyst of size $4 \times 3 \mathrm{~cm}$ under MCL (Figure 3, 4). Scanogram shows varus of almost 8 degrees with lateral subluxation of the tibia (Figure 5).
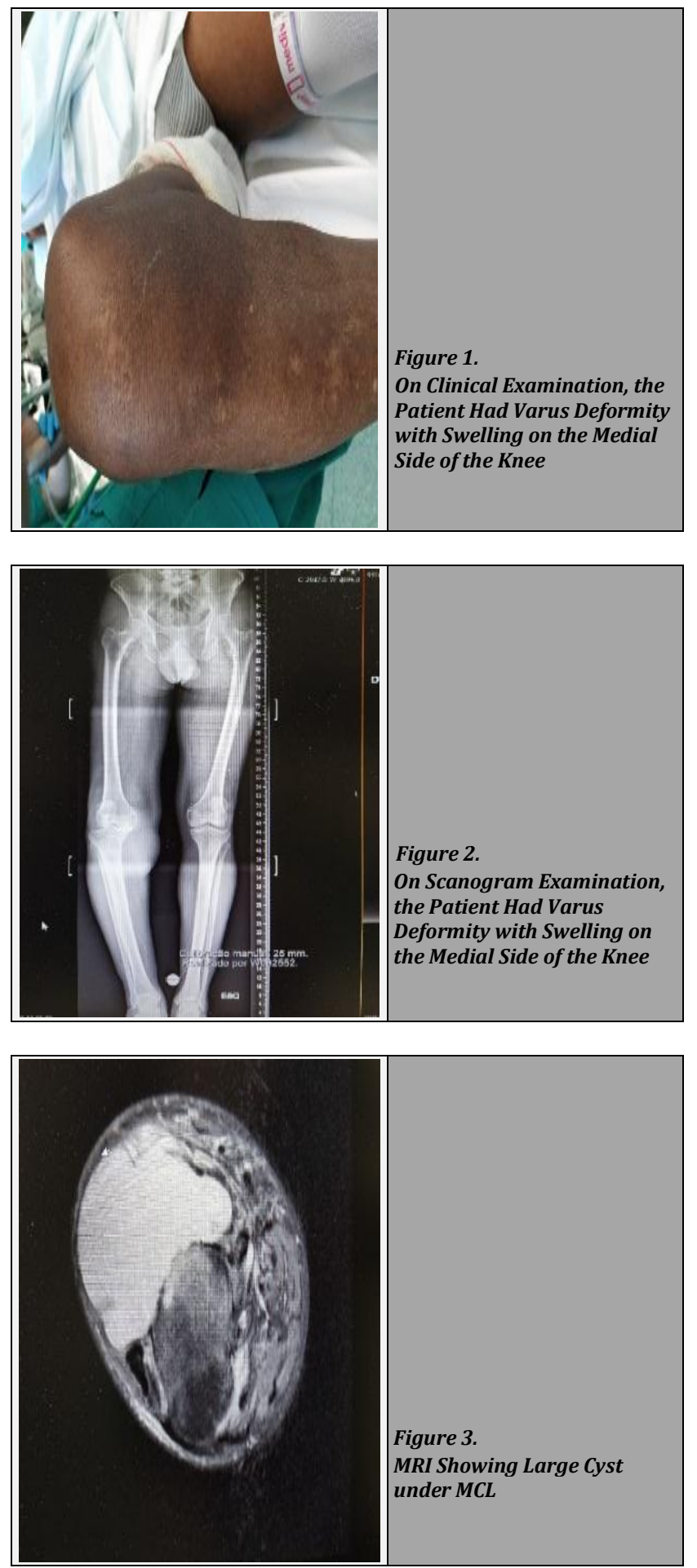
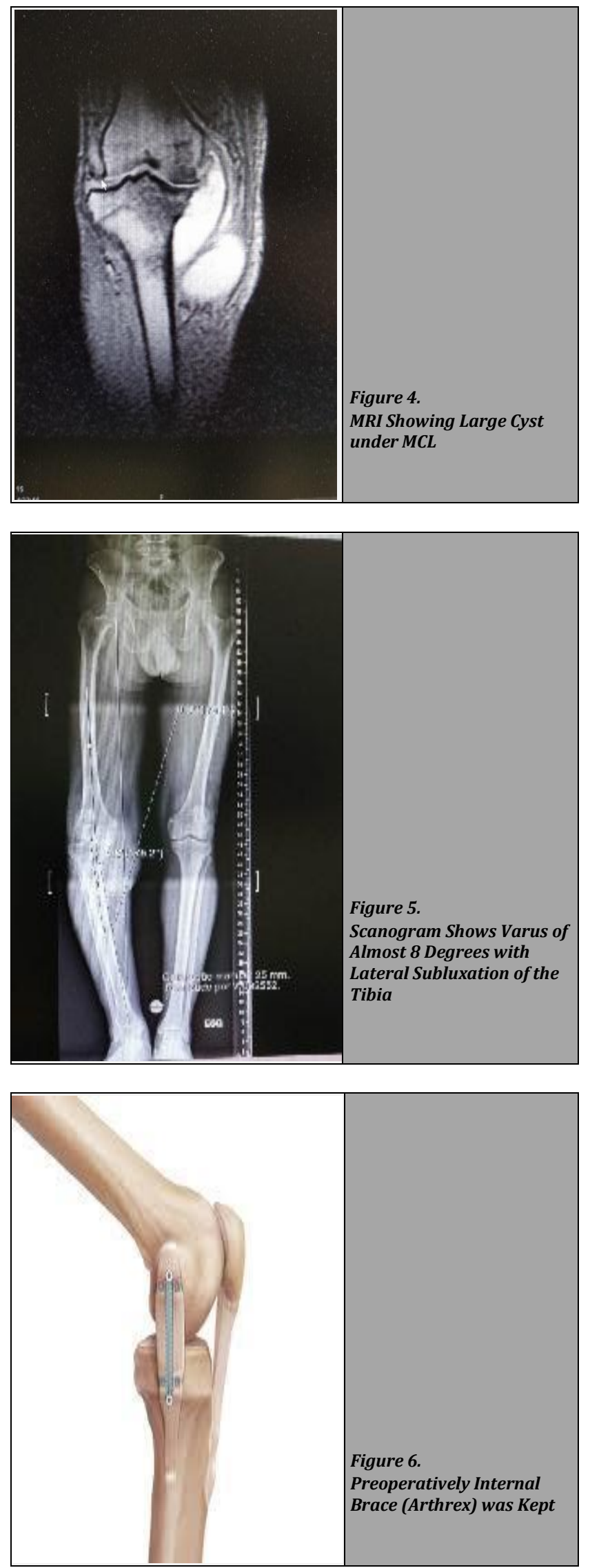

DIFFERENTIAL DIAGNOSIS

Lipoma, bursitis, giant cell tumour. 


\section{DISCUSSION OF MANAGEMENT}

During preoperative planning, internal brace (ARTHREX) (Figure 6) and constrained knee were kept for back up to handle MCL laxity after cyst removal.

Operation was done through a midline incision and medial parapatellar approach. Cyst got drained spontaneously during exposure. Minimal release on the medial side was done. Standard bone cuts were taken as per the preoperative template (sigma $\mathrm{j} \& \mathrm{j}$ ). But during extension lateral gap was big than the medial side. Even after using the largest size insert, lateral laxity was there. The internal brace was used from Arthrex to augment the lateral collateral ligament. His knee was stable after surgery.

Though the deleterious effect of gross instability on prosthetic survival is well documented, the impact of ligament laxity on functional outcomes after total knee arthroplasty was not clearly described in the literature. ${ }^{6}$ In most cases, it can be prevented by using a proper prosthesis and a certified surgical technique. Special consideration should be given to confirmation of diagnosis for which accurate history taking, comprehensive physical examination, and radiographic evaluation are needed. About treatment, an association of the aetiology of instability is essential for establishing proper treatment plans; instability would continue without correction of the cause of initial instability.

Total knee replacement is challenging in cases with abnormal collateral ligament laxity. Ligament laxity can be due to previous trauma, surgery, tumour, or cyst. Bursa under MCL is rare and very few such cases are described in the literature. . $^{8}$ This bursa is a compartment that is elongated vertically, located between the superficial and profound layers of MCL. ${ }^{9}$ Lipoma is another common soft tissue swelling in the lower extremity.10 But they are either cutaneous or intramuscular. In this case, a large cyst of size $4 \times 3 \mathrm{~cm}$ was under the superficial MCL ligament. The association of such a large cyst with severe osteoarthritis knee is not mentioned in the literature.

This patient was operated on through a standard midline longitudinal incision. The cyst was drained as soon as the knife punctured the capsule. After standard bone cuts, there was much laxity of the lateral collateral ligament. This was opposite to our probability of opening of the medial collateral ligament as it was stretched due to the large size of the cyst. This may be probably due to a large varus deformity of 8 degrees leading to more compensatory laxity of lateral collateral ligament. The internal (Arthrex, USA) brace anchor to tight lateral collateral in Gerdy's tubercle and checked in both flexion and extension with trials and highest size insert. An internal brace is a ligament repair bridging concept utilising braided ultrahigh-molecular-weight polyethylene / polyester suture tape and knotless bone anchors to strengthen the ligament. An internal brace provides augmentation during knee medial and posteromedial corner anatomic repair ${ }^{11}$ and allograft ACL reconstruction. ${ }^{12}$ Post-operative period of healing was uneventful.

Total knee replacement in severe osteoarthritis knee with a large cyst under MCL and use of an internal brace for managing ligament laxity with help of an internal brace device is not mentioned in the literature. This is the first case report of such kind and this procedure is highly recommended for managing such problem during TKR.
Ligament balancing is a crucial step of total knee replacement. Lateral collateral ligament laxity is common in severe varus knee and medial collateral laxity is common in the valgus knee. There are very few studies in the literature on the management of abnormal laxity in such patients. Here we report the use of an internal brace in the management of such a condition and report a case of a large cyst under MCL in severe osteoarthritis knee which was finally diagnosed as parameniscal cyst. Internal brace is an excellent option for managing ligament laxity in total knee replacement but keeping hinged prosthesis in back up is essential while operating cases with suspected ligament laxity.

Financial or other competing interests: None.

Disclosure forms provided by the authors are available with the full text of this article at jemds.com.

\section{REFERENCES}

[1] Colizza WA, Insall JN, Scuderi GR. The posterior stabilized total knee prosthesis. Assessment of polyethylene damage and osteolysis after a ten - year minimum followup. J Bone Joint Surg Am 1995;77(11):1713-20.

[2] Fort-Rodriquez DE, Scuderi GR, Insall JN. Survivorship of cemented total knee arthroplasty. Clin Orthop Relat Dis 1997;345:79-86.

[3] Whiteside LA. Selective ligament release in total knee arthroplasty of the knee in valgus. Clin Orthop Relat Dis 1999;367:130-40.

[4] Matsuda S, Miura H, Nagamine R. Knee stability in posterior cruciate ligament retaining total knee arthroplasty. Clin Orthop Relat Res 1999;366:169-73.

[5] Daines BK, Dennis DA, Gap balancing vs. measured resection technique in total knee arthroplasty. Clin Orthop Surg 2014;6(1):1-8.

[6] Paxton EW, Furnes O, Namba RS, et al. Comparison of the Norwegian knee arthroplasty register and a United States arthroplasty registry. J Bone Joint Surg Am 2011;93(Suppl 3):20-30.

[7] Chatra PS. Bursae around the knee joints. Indian J Radiol Imaging 2012;22(1):27-30.

[8] Maeseneer MD, Shahabpour M, Van Roy F, et al. MR imaging of the medial collateral ligament bursa: findings in patients and anatomic data derived from cadavers. AJR Am J Roentgenol 2001;177(4):911-7.

[9] Marra MD, Crema MD, Chung M, et al. MRI features of cystic lesions around the knee. Knee 2008;15(6):423-38.

[10] Beaman FD, Kransdorf MJ, Andrews TR, et al. Superficial soft-tissue masses: analysis, diagnosis and differential considerations. Radiographics 2007;27(2):509-23.

[11] Lubowitz JH, MacKay H, Gilmer B, et al. Knee medial collateral ligament and posteromedial corner anatomic repair with internal bracing. Arthrosc Tech 2014;3(4):e505-8.

[12] Smith PA, Bradley JP, Konicek J, et al. Independent suture tape internal brace reinforcement of bone-patellar tendon-bone allografts: biomechanical assessment in a full-ACL reconstruction laboratory model. J Knee Surg 2020;33(10):1047-54. 